\title{
N.N. Zadeh Chegini, M.V. Fontana, A. Asadi, M. Rugiadi, A.M. Jaia, A. Blanco, L. Ebanista. Estakhr Project: Second Preliminary Report of the Joint Mission of the Iranian Center for Archaeological Research, the Parsa-Pasargadae Research Foundation and the Sapienza University of Rome, Italy
}

\section{Sébastien Gondet}

\section{OpenEdition \\ Journals}

Édition électronique

URL : http://journals.openedition.org/abstractairanica/41258

DOI : 10.4000/abstractairanica.41258

ISSN : 1961-960X

Éditeur :

CNRS (UMR 7528 Mondes iraniens et indiens), Éditions de l'IFRI

Référence électronique

Sébastien Gondet, « N.N. Zadeh Chegini, M.V. Fontana, A. Asadi, M. Rugiadi, A.M. Jaia, A. Blanco, L.

Ebanista. Estakhr Project: Second Preliminary Report of the Joint Mission of the Iranian Center for Archaeological Research, the Parsa-Pasargadae Research Foundation and the Sapienza University of Rome, Italy », Abstracta Iranica [En ligne], Volume 34-35-36 | 2017, document 8, mis en ligne le 15 juillet 2016, consulté le 01 octobre 2020. URL : http://journals.openedition.org/abstractairanica/41258; DOI :

https://doi.org/10.4000/abstractairanica.41258

Ce document a été généré automatiquement le 1 octobre 2020.

Tous droits réservés 
N.N. Zadeh Chegini, M.V. Fontana, A. Asadi, M. Rugiadi, A.M. Jaia, A. Blanco, L. Ebanista. Estakhr Project: Second Preliminary Report of the Joint Mission of the Iranian Center for Archaeological Research, the ParsaPasargadae Research Foundation and the Sapienza University of Rome, Italy

Sébastien Gondet

\section{RÉFÉRENCE}

N.N. Zadeh Chegini, M.V. Fontana, A. Asadi, M. Rugiadi, A.M. Jaia, A. Blanco, L. Ebanista. «Estakhr Project: Second Preliminary Report of the Joint Mission of the Iranian Center for Archaeological Research, the Parsa-Pasargadae Research Foundation and the Sapienza University of Rome, Italy ». Vicino Oriente, 17, 2013, p. 7-20.

Ces deux articles parus successivement dans une revue italienne présentent les résultats préliminaires de deux missions Irano-Italienne, plutôt formée de spécialistes de la période islamique, de prospections et de fouilles sur le site d'EstaĤr où, depuis les années 1930, aucune recherche de terrain d'envergure n'avait été entreprise. Situé à 5 $\mathrm{km}$ au nord de Persépolis, le site mal connu d'EstaHyr correspond à un vaste tepe de plusieurs dizaines d'hectares formé par les ruines d'une agglomération qui a été la capitale du Fārs au tout début de l'époque islamique, rôle qui lui sera ensuite ravi par 
Šīrāz. En parallèle des travaux entrepris à Persépolis dans les années 30, E. Herzfeld puis E.F. Schmidt ont ouvert quelques sondages sur le site, jamais publiés dans le détail, qui ont permis de prouver l'existence de niveaux sassanides. Il est probable que ce site ait été de quelque importance dès l'époque parthe. Enfin la question de l'occupation achéménide de ce secteur, situé entre la terrasse monumentale de Persépolis et sa nécropole royale Naqš-e Rostam, reste entière.

La mission n'a malheureusement pu mener que deux missions, au cours de l'année 2012, puis a été obligé d'abandonner le projet. Ces deux articles présentent un aperçu des travaux et des principaux résultats obtenus sur cette trop courte période. La première mission (article 2012) a essentiellement été consacrée à la prospection topographique et archéologique du site, on notera ici l'absence de céramique sassanide en surface, apparemment sur l'ensemble du site, témoignant de l'énorme épaisseur des niveaux islamiques au-dessus des niveaux pré-islamiques comme l'avaient démontré les sondages de Schmidt. La seconde mission (article 2013) s'est concentrée sur l'étude (prospection géophysique et fouille) d'un possible palais repéré sur des photographies aériennes anciennes à l'ouest de la mosquée principale de la ville. Une longue tranchée a été ouverte entre les deux bâtiments et a permis la mise au jour d'une voie très soigneusement pavée de moellons calcaires et longée par un égout. Il n'aurait donc pas de palais à l'ouest de la mosquée mais les tracés repérés sur les photographies aériennes et les cartes géophysiques correspondraient à ceux du réseau viaire d'un riche quartier. Notons enfin la découverte de quelques fragments d'éléments de colonnes achéménides (une est encore en place) venant de la terrasse de Persépolis, ou de ses alentours immédiats, remployées dans la mosquée voisine. Ces deux articles permettent d'illustrer le grand potentiel de ce site d'abord pour la période islamique, qui reste sous-étudiée dans le Fars, ensuite pour l'histoire de cette province, puisque les modalités et la chronologie de la fondation de cette ville pourrait offrir un éclairage nouveau sur l'occupation d'une région qui n'est certainement pas devenue un no man's land après la chute de l'Empire achéménide.

3 Ce compte rendu concerne également la référence $n^{\circ}$ R5-1N5-7 :

4 M.V. Fontana, S.M. Mireskandari, M. Rugiadi, A. Asadi, A.M. Jaia, A. Blanco, L. Colliva. «Estakhr Project: First Preliminary Report of the Joint Mission of the Iranian Center for Archaeological Research, the Parsa-Pasargadae Research Foundation and the Sapienza University of Rome, Italy ». Vicino Oriente, 16, 2012, p. 167-180.

\section{AUTEURS}

\section{SÉBASTIEN GONDET}

CNRS, Lyon 